\title{
The role of livestock in Africa: are livestock occasionally contributing to famine?
}

\section{By E. R. ØRSкov, Rowett Research Institute, Bucksburn, Aberdeen $A B 29 S B$}

The role of livestock in Africa is complex and varying. Many books have been written on the subject and it is not possible in the present short paper to analyse the many complex relations between animals and humans in Africa. I shall have to resort to generalization and to limited experience gained in North and East Africa through project-identification work for the Food and Agriculture Organization and from discussions with small farmers and colleagues in the field.

First, it is necessary to briefly summarize the main types of farming systems in which animals are kept to serve mankind in Africa. It is often proclaimed that there is an interdependence of human beings and livestock, but it is in fact mostly a one-sided interdependence. The animals are there to serve humans and not vice versa. Animals could exist without humans while the opposite is seldom the case. This also means that any damage to the ecosystem or contribution to famine that can be attributed to animals must be blamed on the socio-economic and political systems and conditions which lead to short-term irresponsible management of animals.

In the following I will briefly summarize the main livestock systems and feedingstuffs used in Africa, then discuss the possible role of the animal in preventing or causing famine. Then a few comments will be made about possible causes of overgrazing and I will discuss whether there are feasible solutions. Finally I will draw attention to some problems of animal production in Africa to whose solution members of the Nutrition Society could usefully contribute.

\section{Livestock systems}

I. Crop farmers. The animals are kept mainly for draught power. This is less common in Africa than in Asia but does occur in riverine areas, particularly rice-growing areas such as Egypt, and also in areas like the Ethiopian highlands. Milk and meat are secondary products. Cattle are not usually kept for the purpose of investment. They are fed mainly on crop by-products like rice straw, etc. and green grass on edges of fields and roads or wasteland adjoining cropping areas.

2. Crop and animal farmers. On these farms, of less importance numerically, cattle are kept for milk production but fed on crop by-products. Here the crops are grown using hand labour, for instance in the banana-coffee belt on the slopes of Mount Kilimanjaro and Mount Meru in Tanzania. Cattle are fed almost exclusively on crop by-products such as banana leaves and stems and maize stover, etc. 
3. Stock-keeping crop farmers. This category of farmers use livestock both for draught power and as a source of milk and meat and also as capital or security for obtaining goods, as symbols of wealth and for meeting dowry obligations at times of marriage. The cattle here are fed partly on crop by-products, but mainly on common grazing land. This applies to many parts of Africa, such as communal areas in Zimbabwe and Zambia, etc. The farmers are sedentary and the livestock usually kept in a corral near the farmhouse at night. The numbers kept vary from a few up to twenty or more.

4. Transhumance farmers. The previous category merges in to transhumance by way of sendentary farmers in which some members of the family take the cattle, camels and small ruminants for grazing in distant areas, to farmers in which the whole family move for part of the year to other areas but usually have a permanent homestead. The farmers usually have a small plot for crops which they grow by hand-hoeing, but the main source of income is the sale of animals when money is needed. The animals give some milk for the family and also meat and sometimes blood. The meat for home consumption is particularly obtained from small ruminants such as goats and sheep. The cattle and camels also play an important role as a source of capital and security as for category 3 .

5. Nomadic farmers. From transhumance to a fully nomadic system there is another gradation in which the families are settled for part of the year to families constantly on the move to graze their animals. The animals here provide milk, meat and blood for home consumption and hides for houses, and they are a source of capital when other consumer products have to be purchased. They also provide security or act as a secure bank to be used when times are hard. Many farmers also keep a greater number of animals as a security against natural catastrophe in the hope that not all animals will be lost in a drought for instance.

Categories 4 and 5 are predominant in the Sahelian areas of Africa which were most affected by the recent drought, though some farmers of category 3 also had severe problems in parts of Zimbabwe and Sudan. For category 4 and particularly category 5, animal products are the staple food and also the principal source of cash income. Two-thirds of the population of Somalia and Mauritania fall into categories 4 and 5 . When feed is scarce for livestock, the availability of human food follows the same pattern. In most Sahelian countries $75 \%$ or more of the population is engaged in agriculture.

This brief description is necessarily very sketchy, but it is important to recognize that animals, particularly cattle and camels, are kept for various purposes ranging from draught power to the provision of security or capital. The feed resources used range from crop by-products to grazing on natural rangeland. Very little concentrate or cultivated pasture is used.

\section{Under what circumstances may animals contribute to famine?}

For categories $I$ and 2 it is possible not only to say that the animals do not contribute to famine, but that they make human existence possible. In riverine areas cattle and buffalo not only cultivate fields, they also draw water for irrigation, 
as in Egypt, and they give some milk for the family. They ensure that adequate land is cultivated. In return they receive mainly crop by-products and so do not compete for human food. Even more critical is the keeping of cattle in rain-fed areas in which the time for cultivation and planting is very short. Frequently planting has to be done within a period of 2 or 3 weeks in order to secure a crop at the end of the rainy season. Here the participation of draught animals is essential in order to cultivate sufficient land to feed the family. Often the land is not very fertile, which also increases the area that has to be cultivated in order to grow enough food for the family.

The recent famine in Ethiopia and Sudan for instance showed very clearly that the importance and need for animals is also recognized by the farmers. One sure sign of impending catastrophe is when prices drop for cattle due to oversupply and particularly when farmers offer female cattle for sale in large numbers. This is the final straw, the last thing that the farmers can part with. It is important to recognize that a famine such as the one in Ethiopia in which there is a large loss of animals is not overcome when the rain comes. For many families it will be many years before they have recovered from the drought since they must build up sufficient surplus by hand labour to be able to buy cattle again. In fact the best form of aid for many of these countries following a drought is to ensure that draught animals become available to them again by soft loans or any other means.

Common to categories $3-5$ are the problems of overgrazing and subsequent deterioration of the land and sometimes bush encroachment, soil erosion and desertification. The causes will be discussed in more detail below. It is important to consider, however, that animals are required for categories 3 and 4 to provide draught power and for categories 4 and 5 also to harvest the vegetation from which animals will produce food for human consumption, such as milk, meat, blood, etc. The only other human existence possible for this type of environment would be that of hunting if the vegetation was to supply products, e.g. meat, on which to exist. The sale of oil by the oil-producing North African and Asian countries allows purchase of food for humans and animals to make existence in deserts possible.

\section{Causes of overgrazing}

The causes of overgrazing are complex and many. Here a few of the most important ones will be mentioned. I shall not deal with changes in climatic conditions because they are inadequately documented and inadequately understood.

Increasing population density. Due mainly to a decreasing child mortality the annual population increase in many parts of Africa is in excess of $3 \%$. According to FAO (1984) the population increase from 1972 to 1981 was $15 \%$ in Chad and $40 \%$ in Somalia. Since each person aspires to own livestock the animal population has increased to exceed the capacity of vegetation to support it even when the rains are good. A season or two of drought and the perennial grasses do not recover and the desert encroaches. The increasing population density also affects the available 
rangeland in other ways. Increasing population density among crop farmers or livestock-owning crop farmers will encroach on the rangelands by cropping the best land since crop land normally receives priority everywhere. The rangeland which can be cropped is also occasionally taken over by large industries producing foods for export.

Common grazing land. Another very complex problem is that of land rights and tenure in many parts of Africa. Most of the rangeland is common grazing and it is difficult to institute grazing policies by individual farmers. Each farmer considers that grazing is free and that if his animals do not graze the land others will do so. This system makes any control of grazing by government almost impossible. However, there are often quite detailed traditional controls regulating the use of common grazings which relate to prevailing weather conditions, etc.

Cattle and camels as capital. It was mentioned in categories 3-5 that many animals are kept as a source of security or as a source of capital. It is seen by most farmers to be the safest investment. This is undoubtedly the case as many town dwellers and civil servants also buy cattle for grazing when they can afford to do so and thus contribute to overgrazing as well. Even if the calving interval is only one calf for every 2 years it is probably a better investment than any bank can yield since the grazing is not given a monetary value. This is particularly a problem in the more industrialized areas such as in the oil-producing states where members of the family in lucrative employment may well invest their accumulated capital in cattle. This again leads to an increased number of cattle being kept and so contributes to overgrazing and eventually limits the amount of land available for grazing.

Enforced settlements of nomads. Whenever governments for political or social reasons are forcing transhumance and nomadic families to settle, the areas around the settlements will almost invariably be overgrazed. Such examples can easily be found in many parts of North Africa (Tunisia, Somalia, etc.) where areas around settlements look more like deserts.

New water holes. The siting of water holes for watering cattle can also give rise to problems of overgrazing. For instance it is quite common that a water hole may be frequented by several families so that the areas around will be totally overgrazed and desert-like. In periods of drought some water holes dry up thus increasing the use of functioning water holes with destruction of grazing for miles around.

Deforestation. Increasing population pressure has increased the requirement for wood for domestic cooking in excess of regeneration of trees and bushes. Consequently many areas are exposed to erosion and elimination of rangeland and feeds for animals.

\section{Are there any solutions to problems of overgrazing?}

First it must be pointed out that the animals are not in themselves the cause of overgrazing. It is the socio-political circumstances which give rise to overgrazing, mainly that of population increase and the keeping of animals as a source of capital and security even by non-pastoralists. Solutions to these problems are very 
complex and require a lot of political skill. The communal land tenure system is such that no individual farmer can be interested in protecting the environment since others will reap the benefit. On the other hand, any approach that encroaches on communal land is hated by nomadic and transhumance people. What is certain is that any control of animal numbers per unit area envisaged by governments must involve the leaders of transhumance and nomadic families in the decision-making process in order to make any system effective and acceptable.

\section{Are areas of Africa underutilized?}

This question is an important one to answer because excess populations could be moved in from other areas. This is being attempted, perhaps rather clumsily, in Ethiopia and Somalia in the wake of famine and war. Here it must be pointed out that vast areas of Africa are underutilized for two main reasons. The first, which is probably more apparent in the northern part of Africa, is the lack of water holes. The animals must be able to get to a water hole within a certain distance from the grazing areas. The other big problem is that of tsetse fly- and tick-borne diseases in the more southern part of Africa.

Access to drinking water. Vast areas of Africa can be exploited by siting new water holes in strategic places; even crop by-products are sometimes not consumed by animals in the dry season because of distances from water holes. Here it must be pointed out that animals vary a great deal in the frequency with which they must drink. Camels for instance (Nicholson, 1985) can walk quite comfortably for 9 d without water, this means that they can cover a vast orbit from a water hole before they need to return to it. A greater number of camels could therefore help to exploit areas of North Africa which today are not exploited. Cattle on the other hand can only tolerate up to 2 or $3 \mathrm{~d}$ without water and, this in turn limits the orbit that they can cover around water holes (though native breeds are more tolerant than European ones). Depending on heritability of this characteristic it may also be possible that cattle could be selected on account of their water economy. This is an area in which there is insufficient information available. Sheep and goats in the area also seem to tolerate more days without water than do many breeds of cattle.

Tsetse fly and tick infestation. Many areas of Africa are not utilized by domestic cattle due to tsetse fly- and tick-borne diseases. Controls of tsetse flies and ticks have been instituted in some areas and a great deal of research is carried out to achieve greater control. Such measures require a great deal of discipline and at the moment small farmers in many areas spend more money on drugs for the cattle than they actually spend on food for them. There are other possible solutions. Wild ruminants and zebras, for instance, are tolerant of tick- and tsetse fly-borne diseases. More effort needs to be spent on finding out how to manage or domesticate wild ungulates with which to harvest the vast areas of Africa which are at the moment underutilized. Tsetse fly and tick infestation also limit use of cropping land insofar that draught animals cannot be used for cultivation of land.

There is no doubt that the areas which are today overgrazed could give rise to a much greater animal production if the animal numbers were reduced. The calving 
interval of the cows is normally 2 years or more; improved fertility would allow the same number of calves to be produced by a smaller breeding stock, thus reducing overgrazing without diminishing productivity. Many castrated males and dry females are kept as a source of capital; alternative forms of sound investment should be sought. At the moment, an increase in feed availability will only increase the numbers of cattle kept, but will not increase the number offered for sale. Common to many nomadic people and livestock-keeping crop farmers, is that they do not wish to sell animals unless they have to for purchase of essential goods, e.g. school fees, etc. When they sell animals they usually sell the oldest and the poorest of them. Feelings of insecurity regarding land tenure lead to unwillingness to invest in capital items other than cattle. They do not see any future in investing in houses, since they may have to move very shortly. Indifference to or lack of goods also means that there is less reason for farmers to want to sell cattle. In each area the constraints are different but the problems of overgrazing are extremely complex and their solution requires many different approaches and much determination. The transhumance and nomadic farmers must be shown that it is to their advantage to co-operate with government to reduce animal numbers and be helped to find other sources of investment which are seen to be equal to that of investing in numbers of cattle.

\section{Challenges for nutritionists}

Although many of the problems of overgrazing in particular are man-made and need to be solved by means that require little knowledge of nutrition, there are many problems relating to animal nutrition whose solution could assist in the prevention of famine and alleviation of rural poverty. I would like therefore in this final section to draw attention to some of the important areas in which more knowledge is urgently required.

Physical work-reproduction interaction. Although draught power is the main product in many animal systems, both in Africa and Asia, there is still relatively little knowledge of many aspects of it, such as interaction of physical work of female animals to food intake and to reproduction and milk yield, etc. A greater use of female animals for draught power could greatly increase productivity from available resources as both milk and meat production could be increased if reproduction could be maintained or planned to coincide with periods of minimal physical work. Development of better tools for cultivation such as the one-ox plough is another advance which may allow fewer or smaller animals to be used for cultivation of a given area of land.

Animal-feed resource interaction. Novel by-products and forages, such as olive-oil wastes and leguminous shrubs, need to be evaluated as feedstuffs. There is evidence to suggest the cattle in rice-growing areas which are given little but rice straw to eat have developed a much larger rumen volume relative to body-weight than ruminants in temperate areas given high-quality feeds (Mould et al. 1982). Yet crossbreeding with animals from temperate areas is encouraged with sometimes disappointing results when feed resources are unaltered. More 
information is required on the physiology of stomach development and the heritability of such characteristics before the more widespread use of exotic and high milk- and meat-producing animals from temperate zones cause more problems in developing countries. The ability to recycle blood urea to the stomach and thus diminish dependence on dietary protein is another characteristic which may be more fully exploited.

Animal-environment interaction. While it is recognized that some animals are well suited for tropical areas and some are not, as far as Africa is concerned more information is required on the mechanisms of body temperature control and water conservation and the heritability of the physiological characteristics concerned. If the ability of cattle to do without water could be extended from 2 to $4 \mathrm{~d}$ it would greatly increase the areas that could be grazed around water holes and thus in many areas increase resource availability and decrease overgrazing.

Animal-disease interaction. Elucidation of mechanisms of resistance to tickand tsetse fly-borne diseases could open up the possibilities of using modern techniques of gene manipulation to useful ends. As mentioned earlier, another approach is to learn how to manage native African animals such as eland, buffalo, impala and zebra which are tolerant to the diseases.

Propensity for fat deposition. In almost all areas of Africa there is a fluctuating supply of nutrients as both the quality and quantity of forage available decrease during the dry season. The most efficient method of preserving feed is in the form of body fat deposited subcutaneously, as in humps (camels and zebu cattle) or tails (sheep) which do not restrict gut volume. The ability of animals to rapidly consume the good-quality grass during the rainy season and accumulate fat need to be further exploited. At the same time easy methods for assessing the amount of preserved feed (fat) need to be developed to evaluate whether supplements are needed during the dry season.

Protein status. Most animals in the tropics are protein deficient during part of the season yet locally-available protein supplements are often exported to provide foreign currency and to overproduce milk in temperate regions from where it may be returned in the form of food aid, often to damage dairy development in the country. Easy methods of assessing protein status in animals by urine or blood sampling would be of great assistance to encourage use of locally-available protein supplements in the most efficient manner.

Improvement of resources. There is an increasing amount of evidence to suggest that the nutritive value of crop by-products, e.g. straw and stover, could be improved without reducing the yield of grain (Tuah et al. 1986). Research in this area is particularly important since crop by-products in categories $I$ and 2 form the greatest proportion of the animals' diet. Simple methods of increasing the nutritive value of straw also need to be further explored together with easy methods of applying non-protein-nitrogen and other deficient nutrients to low-quality roughages and rangeland.

Increasing resource utilization through biogas. In many areas of Africa, trees are removed for firewood with consequent degradation of the environment. Lack of 
trees then leads to the use of cow dung as fuel for domestic cooking which in turn depletes the soil of nutrients. The installation of small units for production of biogas from farm and domestic waste can alleviate this spiralling problem without loss of soil nutrients since they are retained in the biogas slurry and returned to the land.

Development of aquaculture. In riverine areas much food for human consumption can be harvested by recycling animal manure or biogas slurry through fish ponds stocked with carp and tilapia without loss of soil nutrients, since fish ponds can be used in rotation with other crops. Fish and rice can even be grown in the same plot.

Greater use of legumes. The use of leguminous shrubs (Leucaena sp., Glyricidia sp.) or forages (Desmodium sp., Stylosanthes sp., annual Medicago sp., berseem) for the capture of $\mathrm{N}$ for soil improvement and for increasing the quality of forage for animals is not fully exploited. Edges of ponds, fields and roads could be planted with appropriate species. Annual Medicago sp. can also be used to replace fallow as in South Australia (Chatterton \& Chatterton, 1981).

\section{Conclusions}

It is my hope that this very brief and patchy assessment of livestock and their role in famine in Africa can perhaps lead to a greater interest in African problems in particular and rural poverty in general. There are many fascinating problems which not only urgently require a solution for practical reasons but which surprisingly often may reveal questions of fundamental interest. The study of these problems not only allows one to assist in the prevention of famine and alleviation of poverty, but also restores a balance at a time when many nutritionists seem to be more concerned with the relief of problems associated with gluttony.

\section{REFERENCES}

Chatterton, L. \& Chatterton, B. (1981). Outlook on Agriculture 10, 397-402.

Food and Agriculture Organization (1984). World Animal Review 51, 2-I I.

Mould, F. L., Saadullah, M., Hague, Davis C., Dalberg, F. \& $\emptyset$ rskov, E. R. (1982). Tropical Animal Production 7, 174-181.

Nicholson, M. J. (1985). In Workshop on Livestock Policy in Drought-Prone Countries, Khartoum. Rome: Food and Agriculture Organization.

Tuah, A. K., Lufadeju, E. \& Ørskov, E. R. (1986). Animal Production 43, 26r-269. 